\title{
Overexpression of chloride channel-3 (CIC-3) is associated with human cervical carcinoma development and prognosis
}

Yu-tao Guan ${ }^{1,2}$, Yong Xie ${ }^{2}$, Hui Zhou ${ }^{1}$, Hai-yan Shi ${ }^{3}$, Yu-yuan Zhu ${ }^{2}$, Xiao-lu Zhang ${ }^{2}$, Yi Luan ${ }^{1}$, Xi-ming Shen ${ }^{4}$, Yang-ping Chen ${ }^{2}$, Li-jiang $\mathrm{Xu}^{2}$, Zhong-qiu Lin ${ }^{1^{*}}$ and Gang Wang ${ }^{2^{*}}$

\begin{abstract}
Background: Cervical carcinoma is a major gynecological cancer and causes cancer-related deaths in worldwide, the latent pathogenesis and progress of cervical cancer is still under research. ClC-3 may be an important promoter for aggressive metastasis of malignant tumors. In this research, we explore the $\mathrm{ClC}-3$ expression in cervical carcinoma and its underlying clinical significance, trying to illuminate CIC-3 probable function in the neoplasm malignant behavior, development and prognosis.

Methods: Paraffin-embedded cervical $(n=168)$ and lymph node $(n=100)$ tissue specimens were analysed by immunohistochemistry. Fresh human cervical tissue specimens $(n=165)$ and four human cervical cell lines were tested for CIC-3 mRNA and protein expression levels by quantitative real-time PCR and western blotting. The relationship between the expression levels of $\mathrm{ClC}-3$, the pathological characteristics of the carcinoma, and the clinical prognosis were statistically analysed.
\end{abstract}

Results: In normal and precancerous (LSIL, HSIL) cervical tissues as well as cervical carcinoma tissues, both CIC-3 mRNA and protein expression levels increased significantly $(p<0.05)$. The expression level of CIC-3 was closely-related to the histological differentiation ( $p=0.029)$, tumour staging $(p=0.016)$, tumour size $(p=0.039)$, vascular invasion ( $p=0.045)$, interstitial infiltration depth $(p=0.012)$, lymphatic metastasis $(p=0.036)$, and HPV infection $(p=0.022)$. In an in vitro experiment, ClC-3 mRNA and protein were found to be overexpressed both in the HeLa and SiHa cell lines, but low expression levels were detected in the $\mathrm{C}-33 \mathrm{~A}$ and $\mathrm{H} 8$ cell lines $(p<0.05)$. Furthermore, the high expression levels of CIC-3 was significantly correlated to poor survival in cervical carcinoma patients (Log-rank test, $p=0.046$ ).

Conclusions: These data suggest that overexpression of $\mathrm{CIC}-3$ is closely associated with human cervical carcinoma progression and poor prognosis; this suggests that $\mathrm{ClC}-3$ may function as a patent tumour biomarker and a latent therapeutic target for cervical carcinoma patients.

Keywords: Chloride channel-3 (CIC-3), Cervical carcinoma, Development, Prognosis

\footnotetext{
*Correspondence: lin-zhongqiu@163.com; wallace1971@163.com

1 Department of Obstetrics and Gynaecology, Sun Yat-sen Memorial

Hospital of Sun Yat-Sen University, Guangzhou, China

2 Department of Obstetrics and Gynaecology, The First People's Hospital

of Foshan, Foshan, China

Full list of author information is available at the end of the article
} 


\section{Background}

Cervical carcinoma is a major gynaecological cancer that causes thousands of cancer-related deaths in women worldwide; most cervical carcinoma diagnoses occur in developing countries [1]. The most common type of cervical cancer is squamous cell carcinoma (SCC), which develops from low-squamous intraepithelial lesions (LSIL) and high-squamous intraepithelial lesions (HSIL). The main risk factor for cervical carcinoma is papillomavirus (HPV) infection [2]. More than $80 \%$ of women have been infected with HPV, but only a small proportion of women develop cervical cancer. This suggests that some other factors may take part in the pathogenesis of cervical cancer. Therefore, the underlying pathogenesis and progress of cervical cancer is still being investigated.

Studies have found that membrane ion channels play a significant part in the progress and metastasis of malignant tumours [3]. Chloride channels have been documented to promote tumour cell invasion and the formation of brain metastasis in primary brain tumours and glioma [4]; chloride channel-3 (ClC-3) has been proven to take part in cell migration and invasion $[5,6]$, indicating $\mathrm{ClC}-3$ can be a crucial promoter of metastasis.

$\mathrm{ClC}-3$ is a member of the voltage-gated $\mathrm{Cl}-$ channel superfamily [7] and is implicated in the regulation of malignant tumour cell behaviour such as proliferation, migration, invasion, and apoptosis [8-10]. Previously, our studies found that $\mathrm{ClC}-3$ plays a key role in ectopic endometrial cell migration and invasion [5]. Recent studies show that $\mathrm{ClC}-3$ plays an active and vital role in accelerating neoplasm metastasis and may be a prognostic biomarker of tumour dissemination [11]. Oestrogen can activate expression and promote translation of the $\mathrm{ClC}-3$ gene [12], and be responsible for promoting cancer growth [13]. ClC-3 abnormal expression and dysfunction may result in various pathological conditions [14]. Notably, several studies have recently shown that changes in expression of the $\mathrm{ClC}-3$ gene may augment the risk of developing a variety of cancers, including endometrial carcinoma [15], nasopharyngeal carcinoma [16], breast cancer [13] and glioma [17]. ClC-3 has been shown to actively participate in various molecular signal pathways that facilitate the aggressiveness and metastasis of malignant tumours [9]. These data show that $\mathrm{ClC}-3$ may play a crucial role in the occurrence and development of different kinds of cancers.

In this study, we investigate $\mathrm{ClC}-3$ expression in cervical carcinoma and its underlying clinical significance, and we attempt to elucidate the probable function of $\mathrm{ClC}-3$ in malignant neoplasm behaviour, development and prognosis.

\section{Materials and methods}

\section{Ethical authorization}

This research conforms to and acts in accordance with the Enhancing the QUAlity and Transparency Of health Research (EQUATOR) guidelines (http://www.equat ornetwork.org/). All fresh human tissue specimens were collected by informed consent following the requirements of the Research Ethics Committee of the Foshan First People's Hospital from February 2017 to December 2017.

\section{Human tissue collection}

The following cervical tissue specimens were collected and paraffin-embedded: normal cervical tissues $(N, n=30)$, LSIL $(n=35)$, HSIL $(n=43), \operatorname{SCC}(n=60)$, lymph node metastasis positive $(\mathrm{LP}, \mathrm{n}=50)$ and lymph node metastasis negative $(\mathrm{LN}, \mathrm{n}=50)$; the tissues were then evaluated via immunohistochemistry (IHC) by the Pathology Department at the Sun Yat-Sen Memorial Hospital of Sun Yat-Sen University in 2012.

The fresh cervical tissue cohort included cervical tissue $(\mathrm{N}, \mathrm{n}=45)$ from Han Chinese patients who accepted laparoscopic surgery for myoma of the uterus, cervical squamous cell carcinoma (SCC, $\mathrm{n}=60$ ) and the relevant paracancerous normal cervical tissues $(P N, n=60)$ from patients who accepted laparoscopic surgery for cervical cancer confirmed by pathological examination. Specimens were collected from the Department of Gynaecology and Obstetrics (The First People's Hospital of Foshan, Sun Yat-Sen University) during 2017 for protein and mRNA analyses. The relevant paracancerous normal cervical tissues were acquired from $3 \mathrm{~cm}$ over the margin of cervical carcinoma tissues. According to the International Federation of Gynaecological and Obstetrics (FIGO) classification in 2009, the carcinoma patients were in stages from IB to IIA. The patients did not receive any neoadjuvant chemotherapy or radiotherapy before the radical operation.

\section{Cell culture}

HeLa, SiHa, C-33A, H8 and HaCaT cell lines were purchased from GuangZhou Jennio Biotech Co., Ltd. and maintained in cell culture. The HeLa cell line was cultured from cervical adenocarcinoma infected by HPV-18, and the $\mathrm{SiHa}$ cell line was cultured from cervical squamous cell carcinoma infected by HPV-16; the C-33A cell line was cultured from HPV-negative cervical cancer, and H8 was cultured from normal cervical squamous epithelium as normal controls. The $\mathrm{HaCaT}$ cell line was derived from a normal keratinocyte. All cells were cultured with DMEM (GIBCO) containing $10 \%$ foetal calf serum (HyClone, USA) and double antibiotics (100 Units/ml penicillin and $100 \mu \mathrm{g} / \mathrm{ml}$ streptomycin) (GIBCO). The 
cells were incubated in a humidified atmosphere with 5\% $\mathrm{CO} 2$ at $37^{\circ} \mathrm{C}$. The cell lines were authenticated.

\section{HPV test and genotyping}

HPV genomic DNA from the paraffin-embedded cervical carcinoma specimens $(n=65)$ was gathered and tested with the TaKaRa DEXPAT kit (TaKaRa). The HPV DNA and genotypes were tested in the Hospital Clinical laboratory with the HPV GenoArray kit (HybriBio) following the manufacturer's instructions. The assay was able to identify 2 high-risk types $(16,18)$ and other HPV genotypes.

\section{Quantitative real-time PCR}

The mRNA expression levels from fresh cervical tissues and cultured cells were detected with the real-time RTPCR (CFX96 real-time system, Bio-Rad, USA) by using the SYBR Green fluorescence signal test kit according to the manufacturer's instructions. The real-time RT-PCR quantified the mRNA expression levels and was carried out in triplicate for each sample. The cycling conditions were set at $95{ }^{\circ} \mathrm{C}$ for 5 min, followed by 40 cycles at $95{ }^{\circ} \mathrm{C}$ for $10 \mathrm{~s}$, finally, $60^{\circ} \mathrm{C}$ for $5 \mathrm{~s}$ and $72{ }^{\circ} \mathrm{C}$ for $15 \mathrm{~s}$. The sequences of the primer pairs for human $\mathrm{ClC}-3$ were as follows: forward primer $5^{\prime}$-TTGCCTACTATCACC ACGAC- $3^{\prime}$ and reverse primer 5'-GCATCTCCAACC CATTTACT-3'. The human glyceraldehyde-3-phosphate dehydrogenase (GAPDH) gene was amplified as an internal reference using the following primers: $5^{\prime}$-GGTGGT CTCCTCTGACTTCAACA-3' (forward) and 5'-GTT GCTGTAGCCAAATTCGTTGT-3' (reverse). The $2^{-}$ $\Delta \Delta \mathrm{Ct}$ method measured the relative gene expression levels (folds), and all the tests were performed at least three times [5].

\section{Immunohistochemistry assay}

Routine deparaffinization and rehydration were performed for the paraffin-embedded cervical tissue samples. Antigen retrieval was accomplished in $10 \mathrm{mM}$ sodium citrate buffer, $\mathrm{pH} 6.0$, for $10 \mathrm{~min}$ at $92-98^{\circ} \mathrm{C}$; the samples were then treated with $0.3 \% \mathrm{H}_{2} \mathrm{O}_{2}$ for $15 \mathrm{~min}$. Normal goat serum incubation was performed for $20 \mathrm{~min}$ to eliminate nonspecific binding, and after washing with PBS, the samples were incubated in the mouse anti-ClC-3 antibody (1:500 dilution, Abcam, Cambridge, MA, USA) at $4{ }^{\circ} \mathrm{C}$ overnight. The sections were washed with PBS and incubated in biotinylated secondary antibody for $60 \mathrm{~min}$ (1:800 dilution, Beyotime Biotechnology Inc.). The sections were then processed in $\mathrm{ABC}$ solution for $30 \mathrm{~min}$ at $37^{\circ} \mathrm{C}$ prior to treatment with $\mathrm{DAB}\left(3,3^{\prime}\right.$-diaminobenzidine) for $5 \mathrm{~min}$. Counterstaining was performed with
Harris haematoxylin. Positive staining was visualized as brown staining in the cell membrane or the cytoplasm.

The slides were imaged in an inverted microscope. For each slide, images of five random fields were acquired; using the Image-Pro Plus 6.0 image analysis software (Media Cybernetics, Rockville, MD) the mean immunostaining density was measured as described before [5].

For immunochemistry of the cultured cells, cultured cells were incubated in 24-well plates for $24 \mathrm{~h}$ and fixed with paraformaldehyde (4\%) and sucrose $(0.12 \mathrm{M})$ in PBS. The cells were permeabilized with Triton X-100 $(0.5 \%$ in PBS), blocked with $10 \%$ normal sheep serum in PBS for 20 min and treated with the anti-ClC-3 antibody and the biotinylated secondary antibody following the similar procedures as described above.

\section{Western blot assay}

The total protein levels of the fresh cervical tissue specimens $(\mathrm{N}=45, \mathrm{SCC}=60, \mathrm{PN}=60)$ and cultured cells were evaluated by using the BCA assay kit (SinoBio Biotech) to measure protein concentration which was performed following the manufacturer's instructions. Equal amounts of protein were analysed by electrophoresis in 8\% SDS-PAGE gels and transferred to polyvinylidene fluoride membranes (Millipore, Bedford, MA). The membranes were blocked using 5\% skim milk for $2 \mathrm{~h}$ at room temperature. Subsequently, the membranes were incubated with the mouse monoclonal anti-ClC-3 antibody (diluted 1:1000, Abcam) or the mouse anti- $\beta$-actin antibody (diluted 1:1000, Beyotime Biotechnology Inc.) overnight at $4{ }^{\circ} \mathrm{C}$. The membranes were then incubated in the HRP-conjugated secondary antibody for $2 \mathrm{~h}$ at room temperature. The proteins were measured by using the ECL system (CWBIOTECH, China) with the ChemiDoc XRS system (Bio-Rad, Philadelphia, USA).

\section{Statistics}

Statistical analyses were carried out by the SPSS 16.0 software (SPSS Inc., Chicago). The data were presented as the mean \pm standard deviation (SD). The ClC-3 expression status of the clinicopathological samples was determined by using the Pearson's $X^{2}$ test or the Fisher's exact test. The analysis of variance and Student's t-test were used to analyse the significant differences in the $\mathrm{ClC}-3$ expression levels between the groups. The univariate cumulative survival was assessed by the Kaplan-Meier method and the log-rank test. Differences were considered significant at $p<0.05$.

\section{Results}

Increased CIC-3 mRNA expression in cervical cancer tissue

The ClC-3 mRNA expression levels were measured in fresh tissue specimens $(n=165)$ from control (normal, 
non-cervical cancer) cervical specimens, the corresponding paracancerous normal tissues and the matched cancer specimens from the patients with cervical cancer. As displayed in Fig. 1A, the expression of ClC-3 mRNA gradually increased from normal to paracancerous to carcinoma tissues (N: $0.25 \pm 0.0 .06, \mathrm{PN}: 0.68 \pm 0.19$, and SCC: $2.16 \pm 0.53)$. There were significant differences between the normal tissues and paracancerous tissues $(p<0.05)$, and the normal and cancerous tissues $(\mathrm{p}<0.01)$. Furthermore, we found the ClC-3 mRNA expression levels in the cervical cancer tissues were significantly larger than that in the corresponding paracancerous normal tissues $(\mathrm{p}<0.01)$. From the 60 patients with cervical cancer, $81.7 \%$ of cancer specimens $(49 / 60)$ presented an elevated $\mathrm{ClC}-3$ expression level (compared with the paracancerous specimens, 2.45-fold difference, $\mathrm{p}<0.01)$, and $18.3 \%$ of cancer specimens $(11 / 60)$ did not express an elevated level of ClC- 3 mRNA. These results suggest the expression level of $\mathrm{ClC}-3 \mathrm{mRNA}$ is gradually upregulated in paracancerous and cancerous stages and is strongly associated with the evolution of cervical cancer.

\section{Increased CIC-3 protein expression from normal cervical tissue to cervical cancer tissue}

To further confirm whether the $\mathrm{ClC}-3$ protein expression levels change, we identified the $\mathrm{ClC}-3$ expression in cervical tissues at the protein level by immunohistochemistry. The results collected from the paraffin-embedded samples are displayed in Fig. 1B-F. ClC-3 protein was mainly expressed in the cervix squamous epithelial cell cytoplasmic area. While only $10 \%$ of normal tissues expressed the $\mathrm{ClC}-3$ protein, the protein levels were the highest $(85 \%)$ in cervical carcinoma tissues (Table 1a). Importantly, positive $\mathrm{ClC}-3$ protein expression was increased gradually from normal $(10 \%)$ to precancerous (LSIL: $28.6 \%$ and HSIL: $65.1 \%$ ) to carcinoma tissues (85\%) suggesting $\mathrm{ClC}-3$ protein expression is closely associated with the progression of cervical carcinoma $(\mathrm{p}<0.001)$. Simultaneously, $\mathrm{ClC}-3$ protein expression in the cervical carcinoma tissues and the relevant paracancerous normal tissues was detected (Fig. 1G, H). We detected that the $\mathrm{ClC}-3$ protein levels in the normal tissues were very low and very high in the cervical cancer tissues. The positive results represented infiltration of cancer cells. $\mathrm{ClC}-3$ protein expression in the corresponding paracancerous normal tissues was significantly weaker than that in the cervical carcinoma tissues $(85 \%$ vs. $48.3 \%, \mathrm{p}<0.001$ ) (Table $1 \mathrm{~b}$ ). These data correspond with the expression level changes of $\mathrm{ClC}-3 \mathrm{mRNA}$ indicating that $\mathrm{ClC}-3$ gene expression level is closely related to the development of cervical carcinoma.

\section{Increased ClC-3 protein expression in the cancer positive} lymph node

Our previous study found that $\mathrm{ClC}-3$ overexpression facilitates cell migration and invasion [5]. It indicated that high ClC-3 expression levels may be closely related to cancer's ability to metastasize. To verify this assumption, we identified the expression level of $\mathrm{ClC}-3$ at the protein level using IHC in paraffin-embedded specimens derived from cervical cancer patients that were either lymph node metastasis positive $(L P, n=50)$ and lymph node metastasis negative $(\mathrm{LN}, \mathrm{n}=50)$. The data acquired from these paraffin-embedded specimens are displayed in Fig. 2, and we found that the $\mathrm{ClC}-3$ protein level in the lymph nodes of metastatic cancer tissues was significantly higher than that in lymph node tissues without metastatic cancer $(\mathrm{p}<0.05)$. In the 50 lymph node metastasis positive tissues, $86.0 \%$ of the cancer samples (43/50) showed increased expression level of ClC-3 protein (compared with the lymph node metastasis negative samples, 2.39 -fold difference, $\mathrm{p}<0.01$ ), and $14.0 \%$ of the lymph node metastasis positive samples (7/50) did not show an elevated $\mathrm{ClC}-3$ protein expression. These results suggested the expression level of the $\mathrm{ClC}-3$ protein is closely related to the progression of cervical carcinoma.

\section{The relationship between the expression level of $\mathrm{CIC}-3$ and clinical pathological characteristics}

The above results raised the question of whether $\mathrm{ClC}-3$ is related to the clinical features of cervical cancer. The relationship between the expression level of $\mathrm{ClC}-3$ protein and the clinical pathological characteristics was studied in 60 cervical cancer patients with an average of $45.44 \pm 11.3$ years (Table 2). The data showed that the ClC-3 expression level was related to the tumour staging $(p=0.016)$, histological differentiation $(p=0.029)$, tumour size $(p=0.039)$, vascular invasion $(p=0.045)$, interstitial infiltration depth $(p=0.012)$, lymphatic metastasis $(p=0.036)$, and HPV infection $(p=0.022)$. The $\mathrm{ClC}-3$ positive rate gradually increased from stage I to stage II (68.2\% and $94.7 \%$, respectively). However, the specimens in stage III and stage IV were not obtained to distinctly specify the function of $\mathrm{ClC}-3$ expression in advanced cervical carcinoma, which may deviate the ClC-3 positive detection rate. Therefore, more samples are needed to elucidate this problem. Since tumour stage, histological grades, tumour size, vascular invasion, interstitial invasive depth, and lymphatic metastasis are considered key factors for carcinoma migration, invasion and metastasis, the results show that $\mathrm{ClC}-3$ protein expression level is closely related to the malignancy degree of cervical carcinoma. In addition, the infection rate of HPV was $89.1 \%$ in patients with cervical carcinoma. HPV 16 

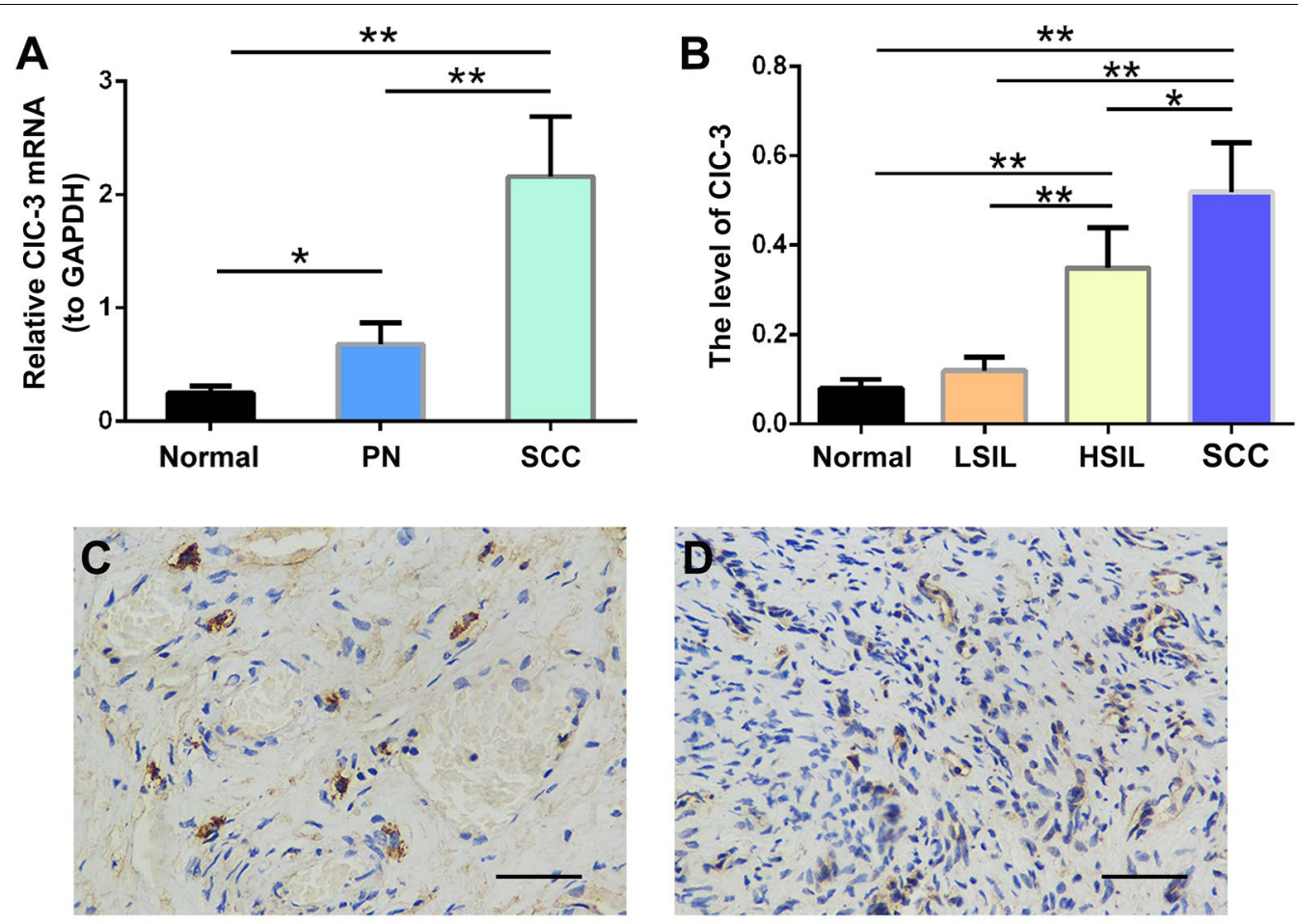

Normal

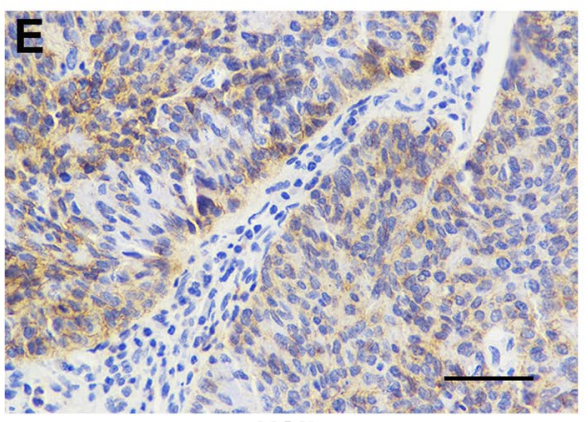

HSIL

LSIL

G
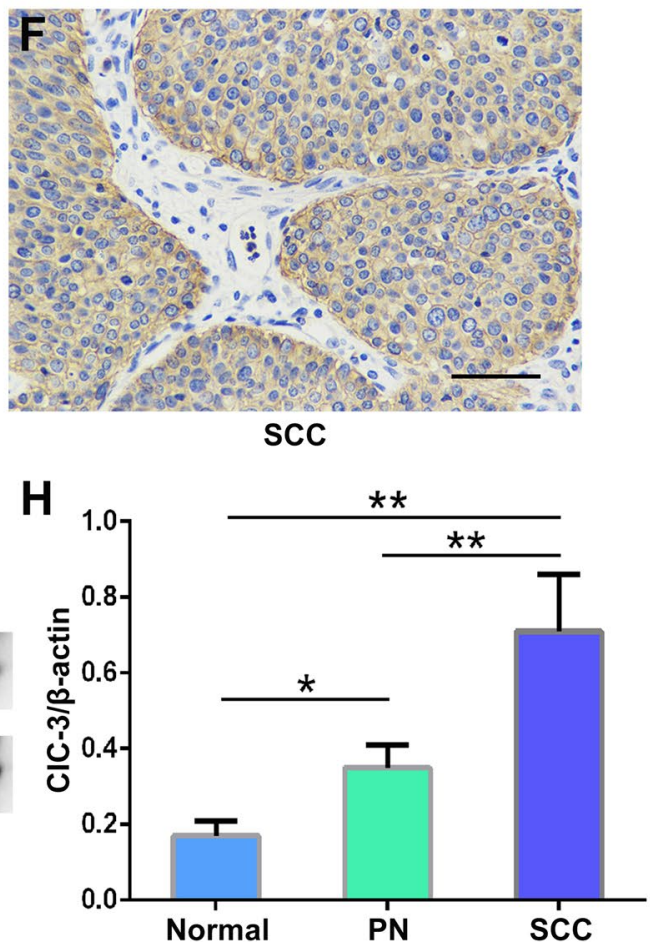

Fig. 1 Increased expression levels of the ClC-3 mRNA and protein in paracancerous and carcinoma tissues. A CIC-3 mRNA expression levels were detected by quantitative real time RT-PCR in the control, non-cervical cancer, cervical samples (normal), the corresponding paracancerous normal tissues (PN) and the matched cancer samples (SCC) from 165 patients with cervical cancer. B Densitometric analysis of the CIC-3 protein expression levels in normal, low-squamous intraepithelial lesions (LSIL), high-squamous intraepithelial lesions (HSIL) and squamous cell carcinoma (SCC) tissues by immunohistochemistry. C-F Images of representative tissues showing the $\mathrm{ClC}-3$ immunohistochemical staining. The main and inserted images were taken by a $\times 40$ objective lens. Scale bars, 50 mm. G The representative western blot analysis of the CIC 3 and $\beta$-actin proteins from normal, PN and SCC tissues. $\mathbf{H}$ Densitometric analysis of CIC3 protein levels in different tissues as detected by western blotting. The data in $\mathbf{A}, \mathbf{B}$ and $\mathbf{E}$ are shown as the mean \pm SD. ${ }^{*} p<0.05,{ }^{* *} p<0.01$ 
Table 1 Expression of $\mathrm{CIC}-3$ protein in cervical tissue

\begin{tabular}{|c|c|c|c|}
\hline Group & Number & $\begin{array}{l}\text { Number of } \mathrm{ClC}- \\
3(+) \text { cases }(\%)^{\mathrm{a}}\end{array}$ & $\mathbf{p}^{\mathbf{b}}$ \\
\hline \multicolumn{4}{|c|}{ a. CIC-3 protein expression in normal, precancerous and cervical cancer } \\
\hline Normal & 30 & $3(10.0)$ & $<0.001$ \\
\hline LSIL & 35 & $10(28.6)$ & \\
\hline HSIL & 43 & $28(65.1)$ & \\
\hline Cancer & 60 & $51(85.0)$ & \\
\hline Total & 168 & $92(54.8)$ & \\
\hline \multicolumn{4}{|c|}{$\begin{array}{l}\text { b. CIC-3 protein expression in the cervical cancer and the correspond- } \\
\text { ing paracancerous normal tissues }\end{array}$} \\
\hline The cervical cancer tissues & 60 & $51(85.0)$ & $<0.001$ \\
\hline $\begin{array}{l}\text { The corresponding paracan- } \\
\text { cerous normal tissues }\end{array}$ & 60 & $29(48.3)$ & \\
\hline Total & 120 & $80(66.7)$ & \\
\hline
\end{tabular}

a $\mathrm{ClC} 3(+)$ denotes overexpression of $\mathrm{ClC} 3$ protein

${ }^{b}$ By Pearson's $X^{2}$ test or Fisher's exact test was the most common in single and multiple HPV infections. The rate of $\mathrm{ClC}-3$ expression in the HPV negative specimens was significantly lower than that in the HPV positive specimens $(40.0 \%$ vs. $89.1 \%, p=0.022)$. These results indicate the expression of $\mathrm{ClC}-3$ protein was closely related to HPV infection in cervical cancer.

\section{CIC-3 is a prognostic survival biomarker for cervical carcinoma patients}

To investigate whether $\mathrm{ClC}-3$ expression influences long-term patient survival, we monitored 60 patients with squamous cervical carcinoma for 60 months and found the average survival time was 48.23 months. From the total, 19 patients died of carcinoma recurrence in the follow-up period (36.7\%). The patient 5 -year cumulative survival rate was $51.0 \%$. As displayed in Fig. 3, compared with the $\mathrm{ClC} 3$ negative expression, the prognosis of cervical cancer was poorer in patients

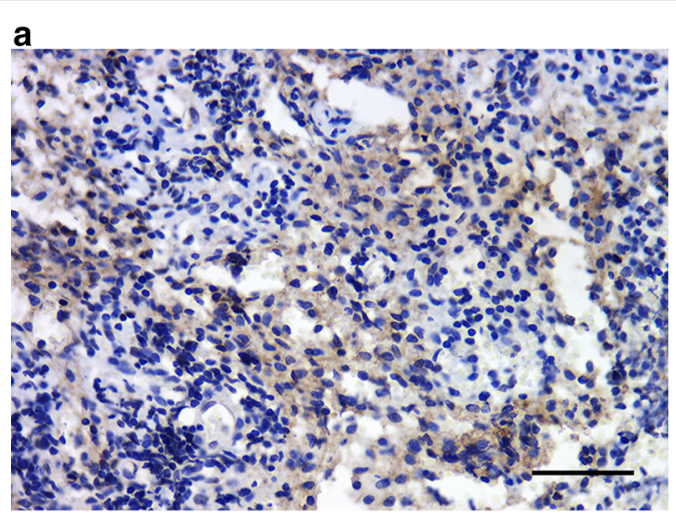

LN b

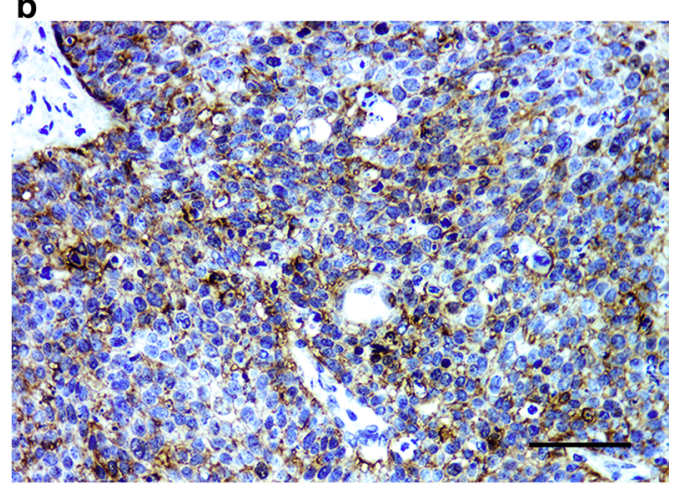

LP

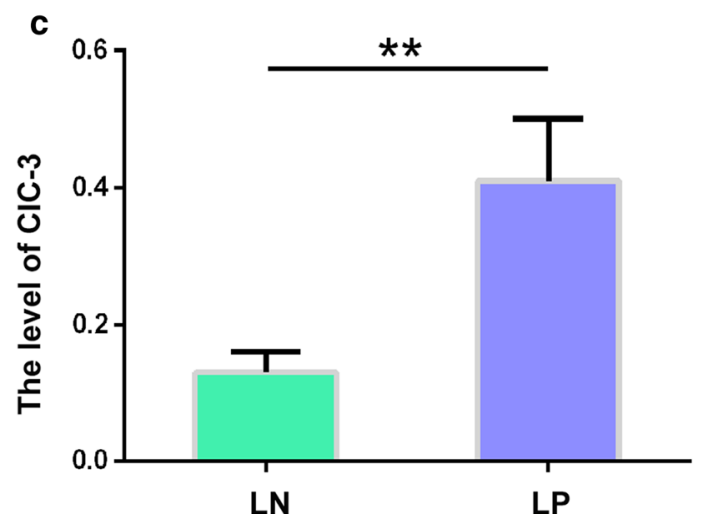

Fig. 2 Increased expression levels of the CIC-3 protein in metastasis positive lymph nodes. $\mathbf{a}$, $\mathbf{b}$ Images from lymph node metastasis positive $(L P)$ and lymph node metastasis negative (LN) tissues showing the CIC-3 immunohistochemical staining. The main and inserted images were taken by using a $\times 40$ objective lens. Scale bars, $50 \mu \mathrm{m}$. c Densitometric analysis of the CIC3 protein levels of LP and LN tissues detected by the immunohistochemistry. The data in $\mathbf{b}$ are shown as the mean \pm SD. ${ }^{* *} p<0.01$ 
Table 2 Cervical cancer patient characteristics and CIC-3 expression

\begin{tabular}{|c|c|c|c|}
\hline Characteristic & Total (60) & $\begin{array}{l}\text { No. of } \mathrm{CIC}-3(+) \\
\text { cases }(\%)^{\mathrm{a}}\end{array}$ & $p^{\mathbf{b}}$ \\
\hline \multicolumn{4}{|l|}{ Age (years) } \\
\hline Mean (SD) & $45.44 \pm 11.3$ & & \\
\hline \multicolumn{4}{|l|}{ Stage } \\
\hline । & 22 & $15(68.2 \%)$ & 0.016 \\
\hline$\|$ & 38 & $36(94.7 \%)$ & \\
\hline \multicolumn{4}{|c|}{ Histological grades } \\
\hline $\mathrm{HDSCC}^{\mathrm{C}}$ & 19 & $13(68.4 \%)$ & 0.029 \\
\hline $\mathrm{MDSCC}^{\mathrm{C}}$ & 25 & $22(88.0 \%)$ & \\
\hline PDSCCC & 16 & $16(100.0 \%)$ & \\
\hline \multicolumn{4}{|l|}{ Tumor size (cm) } \\
\hline$D \leq 4$ & 31 & $23(74.2 \%)$ & 0.039 \\
\hline $\mathrm{D}>4$ & 29 & $28(96.6 \%)$ & \\
\hline \multicolumn{4}{|c|}{ Vascular invasion } \\
\hline Yes & 21 & $21(100.0 \%)$ & 0.045 \\
\hline No & 39 & $30(76.9 \%)$ & \\
\hline \multicolumn{4}{|c|}{ Invasive interstitial depth } \\
\hline$<1 / 2$ & 21 & $14(66.7 \%)$ & 0.012 \\
\hline$\geq 1 / 2$ & 28 & $26(92.9 \%)$ & \\
\hline Whole layer & 11 & $11(100.0 \%)$ & \\
\hline \multicolumn{4}{|c|}{ Lymph node metastasis } \\
\hline Yes & 41 & $38(92.7 \%)$ & 0.036 \\
\hline No & 19 & $13(68.4 \%)$ & \\
\hline \multicolumn{4}{|l|}{ HPV } \\
\hline$(+)$ & 55 & 49 (89.1\%) & 0.022 \\
\hline$(-)$ & 5 & $2(40.0 \%)$ & \\
\hline
\end{tabular}

a $\mathrm{ClC} 3(+)$ denotes overexpression of $\mathrm{ClC} 3$ protein

b By Pearson's $x^{2}$ test or Fisher's exact test

c WDSCC, Highly differentiated squamous carcinoma; MDSCC, moderately differentiated squamous cell carcinoma; PDSCC, poorly differentiated squamous cell carcinoma

with $\mathrm{ClC}-3$ positive tissues as demonstrated by the logrank test ( $\log$-rank $\mathrm{p}=0.046)$. These data suggest that $\mathrm{ClC}-3$ gene expression may be a prognostic biomarker for cervical carcinoma patients.

\section{CIC-3 expression in cervical cancer and normal cervical epithelial cell lines}

To further evaluate expression characteristics of $\mathrm{ClC}-3$ gene, we tested $\mathrm{ClC}-3$ protein and mRNA expression levels of three representative cervical carcinoma cell lines including SiHa, HeLa, C-33A, normal cervical epithelial cell line $\mathrm{H} 8$ and normal keratinocyte cell line $\mathrm{HaCaT}$ via western blotting and quantitative real-time PCR. As displayed in Fig. 4a, increasing expression levels of $\mathrm{ClC}-3$ mRNA were detected in cell lines $\mathrm{SiHa}(4.03 \pm 0.80$, $\mathrm{p}<0.01)$ and HeLa $(3.18 \pm 0.69, \mathrm{p}<0.01)$ but not in C-33A $(1.35 \pm 0.34, \mathrm{p}>0.05)$ compared with that of the $\mathrm{H} 8$ $(1.01 \pm 0.20)$ and $\mathrm{HaCaT}(1.08 \pm 0.21)$ cell lines. However, there was no significant difference between the HeLa and Siha cell lines $(\mathrm{p}>0.05)$.

Furthermore, we measured the $\mathrm{ClC}-3$ protein level in HeLa, SiHa, C-33A, H8 and HaCaT cell lines by western blot and immunohistochemistry analysis (Fig. 4b, c). The data showed the expression levels of $\mathrm{ClC}-3$ protein were consistent with the $\mathrm{ClC}-3$ mRNA expression levels, suggesting that $\mathrm{ClC}-3$ protein levels in HeLa and $\mathrm{SiHa}$ cells were also significantly higher in $\mathrm{H} 8$, $\mathrm{HaCaT}$ and $\mathrm{C}$-33A cells; further, the $\mathrm{ClC}-3$ protein stain was mainly observed in the cytoplasmic area. These data were consistent with in vivo data and suggested that $\mathrm{ClC}-3$ is overexpressed in $\mathrm{SiHa}$ and HeLa but not C-33A human cancer cell lines, and $\mathrm{H} 8$ and $\mathrm{HaCaT}$ cell lines show low expression of $\mathrm{ClC}-3$.

\section{Discussion}

Although $\mathrm{ClC}-3$ plays a well-known and major role in multiple cellular functions, the function of $\mathrm{ClC}-3$ in the progression of cervical cancer has not been well studied. The present study investigated the relationship between the $\mathrm{ClC}-3$ gene expression levels and its underlying clinical significance in human cervical carcinoma to illustrate its impact in the progression of cervical cancer.

ClC-3 has been confirmed to play an important role in cell volume, proliferation, migration and invasion of diversified tumour cells. In the present study, we found that: (i) Expression levels of ClC-3 mRNA and protein are significantly increased by $60 \%$ in paracancerous and cervical carcinoma tissues. The $\mathrm{ClC}-3$ protein is expressed mainly in cervical epithelial cell cytoplasm, indicating $\mathrm{ClC}-3$ is closely associated with cervical epithelial cell homeostasis and malignancy; (ii) We discovered the expression of $\mathrm{ClC}-3$ was closely associated with patient clinical pathological characteristics, suggesting $\mathrm{ClC}-3$ may be a potential biomarker for cervical carcinoma. Furthermore, overexpression of $\mathrm{ClC}-3$ was significantly related to poor survival in cervical carcinoma, indicating it may be a latent predictor of cervical carcinoma prognosis; (iii) In vitro, ClC-3 was highly expressed in both $\mathrm{SiHa}$ and HeLa cell lines but it was expressed weakly in C-33A and H8 cell lines. Since C-33A derives from HPV negative cervical cancer, the carcinoma cells biological behaviour could change greatly. Taken together, we 


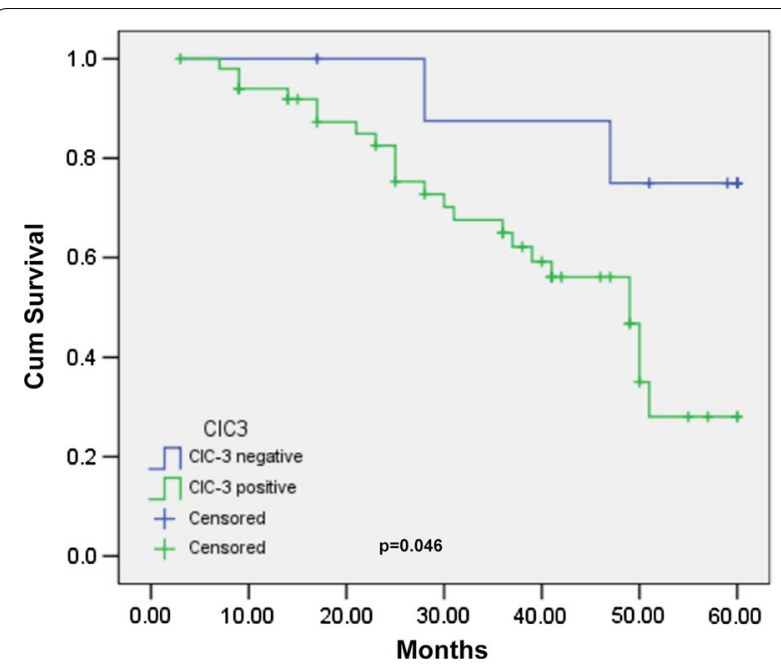

Fig. 3 The relationship between CIC-3 expression and cumulative survival in cervical cancer patients. The Kaplan-Meier curve shows that expression of $\mathrm{ClC}-3$ is oppositely correlated with the 5 -year cumulative survival rate (Log-rank $\mathrm{p}=0.046) .1$ : $\mathrm{ClC}-3$ negative expression; 2: $\mathrm{ClC}-3$ positive expression

conjecture that $\mathrm{ClC}-3$ may be associated with distant tumour metastasis.

Though there are many studies that investigate the roles of $\mathrm{ClC}-3$ in the pathogenesis and pathophysiology of normal and cancer cells, the functions of $\mathrm{ClC}-3$ in human cervical cancer progression are not well known. The $\mathrm{ClC}-3$ gene is considered to be related to multiple tumours. The migration and invasion of tumour cells are primary processes in neoplasm metastasis [18], which requires changes in the tumour cell volume that demands ion channels to regulate ions and water through the plasma membrane [19]. Several studies showed that $\mathrm{ClC}-3$ takes part in the regulation of cell volume changes and volume-regulated chloride currents which positively correlated with cell migration and invasion in cancer cells; this function disappeared after the knockout of ClC-3 [20-22]. In addition, glioma cells invade the normal brain by means of the activities of $\mathrm{ClC}-3$ ion channels that promote cell volume dynamic regulation. $\mathrm{ClC}-3$ is highly expressed on the human glioma cell plasma membrane, and its activity is regulated by phosphorylation via $\mathrm{Ca}(2+) /$ calmodulin-dependent protein kinase II (CaMKII) [23]. Downregulated ClC-3 expression by shRNA can decrease $\mathrm{Ca}^{2+}$-activated chloride current regulation through CaMKII and reduce bradykinin-induced human glioma cell migration. $\mathrm{ClC}-3$ is located in the cytoplasm, nuclei, and plasma membrane of nasopharyngeal cancer (CNE-2Z) cells [24]; inhibition of $\mathrm{ClC}-3$ protein expression was found to inhibit CNE-2Z cell proliferation and migration [25]. ClC-3 can move between the cytoplasm and cytoplasmic membrane; high expression of $\mathrm{ClC}-3$ on the cell membrane may play a role in regulating cell volume [26] and facilitate tumour cell metastasis [27]. In our study, the localization of $\mathrm{ClC}-3$ seems to differ depending on lymph node metastasis; $\mathrm{ClC}-3$ is mainly expressed in the cytoplasm in lymph node cells without tumour metastasis, while $\mathrm{ClC}-3$ is mainly expressed in the cytoplasmic membrane in lymph node cells with tumour metastasis (Fig. 2). We speculated that $\mathrm{ClC}-3$ was involved in the cell volume regulation of enlarged lymph nodes with tumour metastasis. These data suggest that $\mathrm{ClC}-3$ plays a crucial role in human tumour cell migration and invasion. In our present study, it has been demonstrated that $\mathrm{ClC}-3$ may be closely associated with cervical cancer metastasis.

Our study also found that $\mathrm{ClC}-3$ expression was related to cervical cancer HPV infection. The potential mechanism is still unclear. Interestingly, researches have shown that $\mathrm{Cl}$ - currents activated by volume-sensitive chloride channels may play a crucial role leading to regulatory volume decrease (RVD) in human cervical cancer [28], Ano1 is a $\mathrm{Ca}^{2+}$ activated $\mathrm{Cl}(-)$ channel that produces $\mathrm{Ca}^{2+}$ activated $\mathrm{Cl}(-)$ currents and is related to the human papilloma virus (HPV) infection and cancer [29]. This study suggests that $\mathrm{Cl}(-)$ currents may be involved in the process of HPV infection. $\mathrm{ClC}-3$ is a member of the $\mathrm{ClC}$ superfamily of voltage-sensitive $\mathrm{Cl}-$ channels [30], a regulator of the volume-sensitive $\mathrm{Cl}-$ channel chloride currents [27] and may be responsible for HPV infection and cervical cancer development, although more research is needed to confirm this in the future.

Interestingly, we found a positive association between the expression of $\mathrm{ClC}-3$ and the survival time. There are a few studies on $\mathrm{ClC}-3$ and cancer survival time. Wang [9] found that $\mathrm{ClC}-3$ was highly expressed in glioma tissues and was positively related to histological grade. Glioma patients with lower $\mathrm{ClC}-3$ expression had a longer survival time, whereas patients with higher $\mathrm{ClC}-3$ expression had a shorter survival time. ClC-3 expression is associated with invasion and metastasis, which may have a potential impact on survival [17]. Using ShClC-3 adenovirus, the $\mathrm{ClC}-3$ expression was downregulated, which can significantly reduce glioma cell volume-regulated chloride currents, reduce MMP-9 and MMP-3 expression by inhibiting the transcriptional activity of Nuclear Factor-kappa B (NFkappa $\mathrm{B}$ ), and reduce the migration and invasion ability of glioma cells [9]. Xu [11] also reported that cytoplasmic $\mathrm{ClC}-3$ overexpression is positively correlated with cervical cancer metastasis, and patients with highgrade $\mathrm{ClC}-3$ expression in the cytoplasm showed poor survival. A possible mechanism involves $\mathrm{ClC}-3$ overexpression in the cytoplasm of metastatic cancer cells 

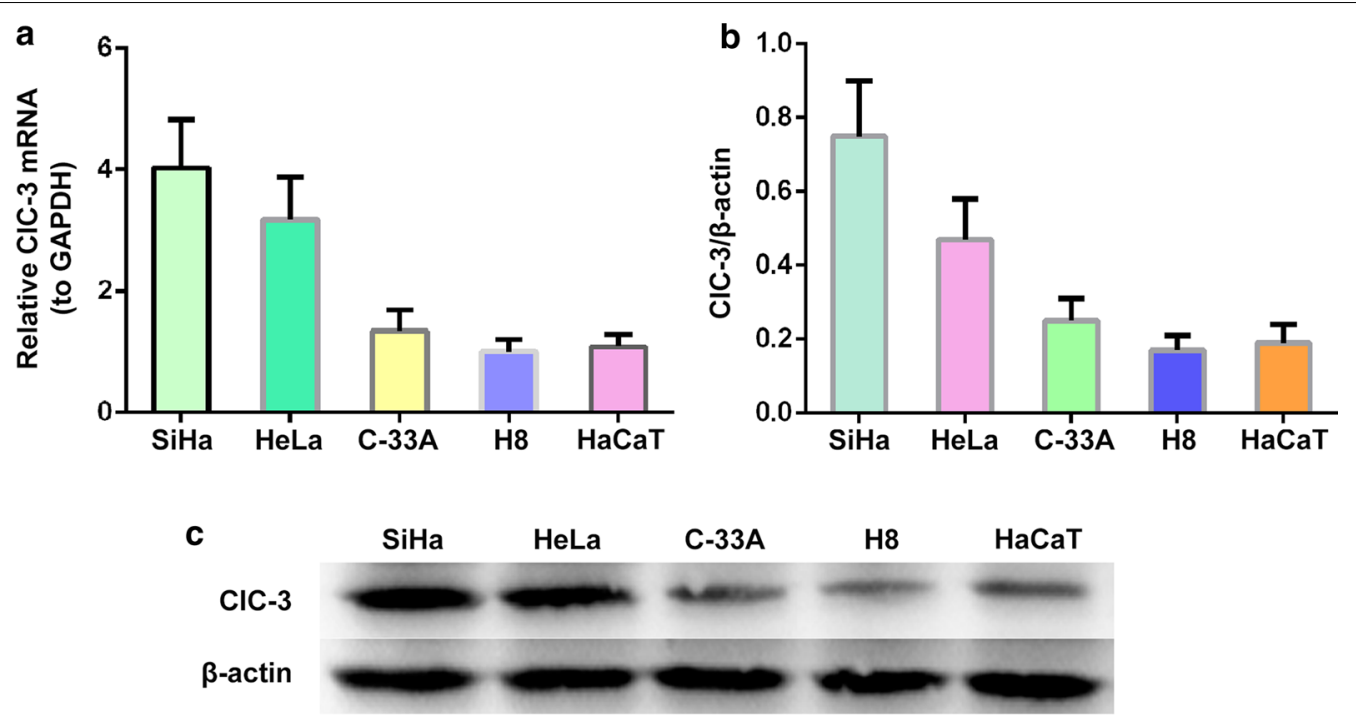

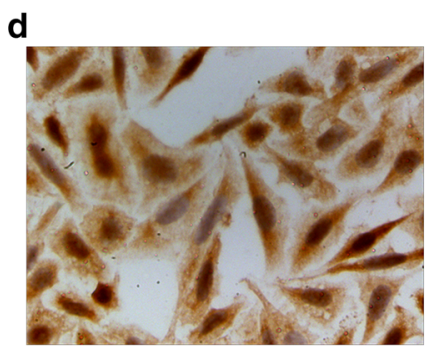

$\mathrm{SiHa}$

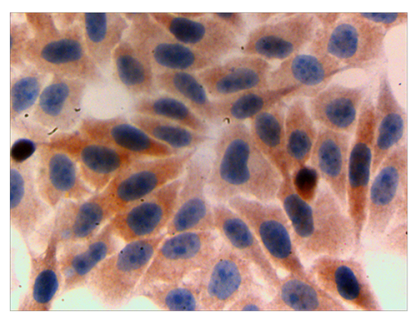

HeLa

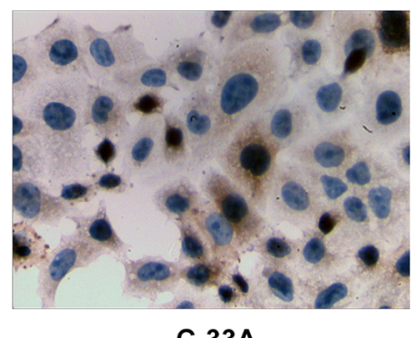

C-33A

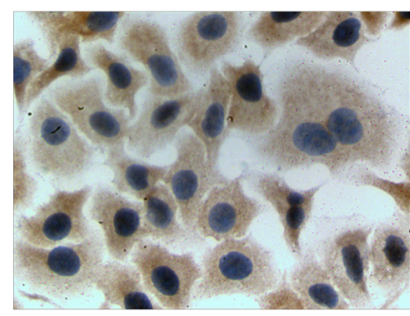

H8

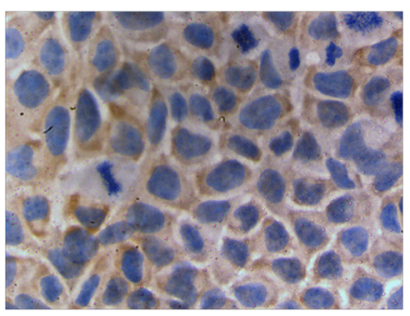

$\mathrm{HaCaT}$

Fig. 4 Increased expression of the CIC-3 mRNA and protein in SiHa and HeLa cell lines. a CIC-3 mRNA expression levels detected by quantitative real time RT-PCR in the SiHa, HeLa, C-33A, normal cervical epithelial cell line $\mathrm{H} 8$ and normal keratinocyte cell line HaCaT. b Densitometric analysis of the $\mathrm{ClC}-3$ protein expression levels in $\mathrm{SiHa}$, HeLa, C-33A, normal cervical epithelial cell line $\mathrm{H} 8$ and normal keratinocyte cell line HaCaT by western blotting. $\mathbf{c}$ The representative western blot of the $\mathrm{ClC} 3$ and $\beta$-actin proteins in the SiHa, HeLa, C-33A, H8 and HaCaT cell lines. The data in a and $\mathbf{b}$ are shown as the mean \pm SD. $\mathbf{d}$ Images of the SiHa, HeLa, C-33A, normal cervical epithelial cell line H8 and normal keratinocyte cell line HaCaT, show the $\mathrm{CIC}-3$ immunohistochemical staining, respectively

and regulation of membrane ruffling by adjusting keratin 18 phosphorylation and controlling recirculation of beta1 integrin, which expedited cell migration and tumour metastasis. Furthermore, $\mathrm{ClC}-3$ was located at different sites in different cell cycle and proliferative states. ClC-3 was mainly located in the cytoplasm during the late G2 DNA synthesis before active mitosis and hyperplasia [26]. In our study, we discovered that the localization of the chloride channel-3 is mainly in the cytoplasm of cervical cancer cells rather than the cytoplasmic membrane (Fig. 1F), and patients with overexpression of $\mathrm{ClC}-3$ had significantly poor survival, indicating it may be an underlying predictor for cervical cancer prognosis. 


\section{Conclusions}

In conclusion, our results provide, for the first time, clinical and experimental evidence that $\mathrm{ClC}-3$ expression is closely associated with cervical carcinoma development and poor survival, indicating $\mathrm{ClC}-3$ may be a patent tumour marker, an expected prognostic indicator and a latent therapeutic target for cervical carcinoma.

\begin{abstract}
Abbreviations
CIC-3: chloride channel-3; IHC: immunohistochemistry assay; SCC: squamous cell carcinoma; LSIL: low-squamous intraepithelial lesions; HSIL: high-squamous intraepithelial lesions; HPVs: human papillomaviruses; MMP: matrix metalloproteinases; DAB: diaminobenzidine; DMEM: Dulbecco's modified Eagle's medium; ECL: enhanced chemiluminescence; HRP: horseradish peroxidase; IHC: immunohistochemistry; NC: negative control; PN: paracancerous normal cervical tissues; NF-kB: nuclear factor kappa-light-chain-enhancer of activated B cells; LP: lymph node metastasis positive; LN: lymph node metastasis negative; qRT-PCR: quantitative real-time PCR; SD: standard deviation; SDS-PAGE: sodium dodecyl sulfate polyacrylamide gel electrophoresis.
\end{abstract}

\section{Authors' contributions}

Y-TG, Z-QL and GW designed the research. HZ, Y-YZ, X-LZ and YL performed experiments and analyzed data. Y-PC and L-JX contributed to sample collection. H-YS and X-MS performed pathology detection. All authors read and approved the final manuscript.

\section{Author details}

${ }^{1}$ Department of Obstetrics and Gynaecology, Sun Yat-sen Memorial Hospital of Sun Yat-Sen University, Guangzhou, China. ${ }^{2}$ Department of Obstetrics and Gynaecology, The First People's Hospital of Foshan, Foshan, China. ${ }^{3}$ Department of Pathology, The First People's Hospital of Foshan, Foshan, China. ${ }^{4}$ Department of Pathology, Sun Yat-Sen Memorial Hospital of Sun YatSen University, Guangzhou, China.

\section{Acknowledgements}

The authors thank Wei Luo (Department of Clinical Research Institute, The First People's Hospital of Foshan) for experimental support.

\section{Competing interests}

The authors declare that they have no competing interests.

\section{Availability of data and materials}

All data and materials can be provided upon request.

\section{Consent for publication}

The authors agree to publish this manuscript.

\section{Ethics approval and consent to participate}

This study was approved by the Ethics Committee of Foshan First People's Hospital.

\section{Funding}

This work was supported by the Science and Technology Programs of Foshan (No. 2017AB002801) and the Medical Research Foundation of Guangdong Province, China (No. B2018034).

\section{Publisher's Note}

Springer Nature remains neutral with regard to jurisdictional claims in published maps and institutional affiliations.

Received: 10 October 2018 Accepted: 24 December 2018 Published online: 08 January 2019

\section{References}

1. Lee H, Kang Y, Ju W. Cervical cancer screening in developing countries: using visual inspection methods. Clin J Oncol Nurs. 2016;20(1):79-83.

2. Piroozmand A, Mostafavi Zadeh SM, Madani A, et al. The association of high risk human papillomaviruses in patients with cervical cancer: an evidence based study on patients with squamous cell dysplasia or carcinoma for evaluation of 23 human papilloma virus genotypes. Jundishapur J Microbiol. 2016;9(4):e32728.

3. Klumpp L, Sezgin EC, Eckert F, et al. Ion channels in brain metastasis. Int J Mol Sci. 2016;17(9):1513.

4. Sontheimer H. An unexpected role for ion channels in brain tumor metastasis. Exp Biol Med. 2008;233(7):779-91.

5. Guan YT, Huang YQ, Wu JB, et al. Overexpression of chloride channel-3 is associated with the increased migration and invasion ability of ectopic endometrial cells from patients with endometriosis. Hum Reprod. 2016;31(5):986-98.

6. Cuddapah VA, Turner KL, Seifert S, et al. Bradykinin-induced chemotaxis of human gliomas requires the activation of kca3.1 and clc-3. J Neurosci. 2013;33(4):1427-40.

7. Duan DD. The clc-3 chloride channels in cardiovascular disease. Acta Pharmacol Sin. 2011;32(6):675-84.

8. Du S, Yang L. Clc-3 chloride channel modulates the proliferation and migration of osteosarcoma cells via akt/gsk3beta signaling pathway. Int J Clin Exp Pathol. 2015;8(2):1622-30.

9. Wang B, Xie J, He HY, et al. Suppression of clc-3 chloride channel reduces the aggressiveness of glioma through inhibiting nuclear factor-kb pathway. Oncotarget. 2017;8(38):63788-98.

10. Fan F, Liu T, Wang $X$, et al. Clc-3 expression and its association with hyperglycemia induced ht22 hippocampal neuronal cell apoptosis. J Diabetes Res. 2016;2016:2984380.

11. Xu B, Jin X, Min L, et al. Chloride channel-3 promotes tumor metastasis by regulating membrane ruffling and is associated with poor survival. Oncotarget. 2015;6(4):2434-50.

12. Deng Z, Peng S, Zheng Y, et al. Estradiol activates chloride channels via estrogen receptor-alpha in the cell membranes of osteoblasts. Am J Physiol Cell Physiol. 2017;313(2):C162-72.

13. Yang H, Ma L, Wang Y, et al. Activation of clc-3 chloride channel by 17 beta-estradiol relies on the estrogen receptor alpha expression in breast cancer. J Cell Physiol. 2018;233(2):1071-81.

14. Oshima T, Ikeda K, Furukawa M, et al. Expression of the voltage-dependent chloride channel clc-3 in human nasal tissue. ORL J Otorhinolaryngol Relat Spec. 2001;63(2):82-6.

15. Li M, Wu DB, Wang J. Effects of volume-activated chloride channels on the invasion and migration of human endometrial cancer cells. Eur J Gynaecol Oncol. 2013;34(1):60-4.

16. Ye D, Luo H, Lai Z, et al. Clc-3 chloride channel proteins regulate the cell cycle by up-regulating cyclin d1-cdk4/6 through suppressing p21/p27 expression in nasopharyngeal carcinoma cells. Sci Rep. 2016;6:30276.

17. Qin C, He B, Dai W, et al. The impact of a chlorotoxin-modified liposome system on receptor $\mathrm{mmp}-2$ and the receptor-associated protein clc-3. Biomaterials. 2014;35(22):5908-20.

18. Shin H, Kim D, Helfman DM. Tropomyosin isoform tpm 2.1 regulates collective and amoeboid cell migration and cell aggregation in breast epithelial cells. Oncotarget. 2017;8(56):95192-205.

19. Kim MJ, Cheng G, Agrawal DK. Cl-channels are expressed in human normal monocytes: a functional role in migration, adhesion and volume change. Clin Exp Immunol. 2004;138(3):453-9.

20. Mao J, Chen L, Xu B, et al. Suppression of clc-3 channel expression reduces migration of nasopharyngeal carcinoma cells. Biochem Pharmacol. 2008;75(9):1706-16.

21. Lemonnier L, Shuba $Y$, Crepin A, et al. Bcl-2-dependent modulation of swelling-activated $\mathrm{Cl}$ - current and $\mathrm{cl}$ - 3 expression in human prostate cancer epithelial cells. Cancer Res. 2004;64(14):4841-8.

22. Habela CW, Olsen ML, Sontheimer H. Clc3 is a critical regulator of the cell cycle in normal and malignant glial cells. J Neurosci. 2008;28(37):9205-17. 
23. Cuddapah VA, Sontheimer H. Molecular interaction and functional regulation of clc-3 by ca2+/calmodulin-dependent protein kinase ii (camkii) in human malignant glioma. J Biol Chem. 2010;285(15):11188-96.

24. Zhang H, Zhu L, Zuo W, et al. The clc-3 chloride channel protein is a downstream target of cyclin d1 in nasopharyngeal carcinoma cells. Int J Biochem Cell Biol. 2013;45(3):672-83.

25. Xu B, Mao J, Wang L, et al. Clc-3 chloride channels are essential for cell proliferation and cell cycle progression in nasopharyngeal carcinoma cells. Acta Biochim Biophys Sin. 2010:42(6):370-80.

26. Shen MR, Wu SN, Chou CY. Volume-sensitive chloride channels in the primary culture cells of human cervical carcinoma. Biochim Biophys Acta. 1996;1315(2):138-44.
27. Sirianant L, Ousingsawat J, Tian Y, et al. Tmc8 (ever2) attenuates intracellular signaling by $\mathrm{zn}^{2+}$ and $\mathrm{ca}^{2+}$ and suppresses activation of $\mathrm{Cl}$-currents. Cell Signal. 2014;26(12):2826-33.

28. Wang $\mathrm{H}$, Wang $\mathrm{R}$, Wang $\mathrm{Z}$, et al. Clc-3 chloride channel functions as a mechanically sensitive channel in osteoblasts. Biochem Cell Biol. 2015;93(6):558-65.

29. Mao J, Yuan J, Wang L, et al. Tamoxifen inhibits migration of estrogen receptor-negative hepatocellular carcinoma cells by blocking the swelling-activated chloride current. J Cell Physiol. 2013;228(5):991-1001.

30. Wang H, Wang R, Wang Z, Liu Q, Mao Y. Duan X: CIC-3 chloride channel functions as a mechanically sensitive channel in osteoblasts. Biochemistry and cell biology = Biochimie et biologie cellulaire. 2015;93(6):558-65.
Ready to submit your research? Choose BMC and benefit from:

- fast, convenient online submission

- thorough peer review by experienced researchers in your field

- rapid publication on acceptance

- support for research data, including large and complex data types

- gold Open Access which fosters wider collaboration and increased citations

- maximum visibility for your research: over $100 \mathrm{M}$ website views per year

At BMC, research is always in progress.

Learn more biomedcentral.com/submissions 